\title{
COVID-19 Vaccine Priority for People With Neurologic and Rare Diseases
}

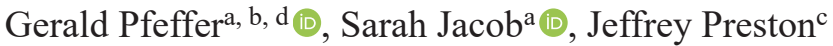

As vaccination programmes against coronavirus disease 2019 (COVID-19) are expanded, substantial variation in the prioritisation of different groups is apparent both between countries but also interprovincially within Canada. In this editorial, we bring attention to the need to prioritize individuals with neurologic and rare disorders for vaccination.

\section{Neurologic Complications From COVID-19}

The pandemic illness caused by the severe acute respiratory syndrome coronavirus 2 (SARS-CoV-2) has led to the identification of numerous common neurologic complications, which may result directly or indirectly from infection [1]. The most well-known neurologic symptom is anosmia/dysgeusia (loss of sense of smell/taste) [2] whose uniqueness to SARS-CoV-2 has been debated [3]; involvement of skeletal muscles is also very common and fortunately mild in most cases (predominantly myalgias), although myositis and rhabdomyolysis are described $[4,5]$. Rarely, more significant neurologic complications arise [6]. In the central nervous system, some of the described phenotypes include encephalopathy [7], neuroimmunological syndromes [8], and myoclonus/ataxia [9]. Ischemic stroke appears to have a more severe outcome in COVID-19 patients but was not more common in a recent large series [10]. Peripheral nervous system complications mainly relate to above-mentioned complications of skeletal muscle, as well as variants of Guillain-Barré syndrome [11-13]. Mononeuritis multiplex has been described with high prevalence in a series of critically ill patients with COVID-19 [14], which is a group of patients in whom neurologic impairments may be difficult

Manuscript submitted April 12, 2021, accepted April 15, 2021

Published online April 20, 2021

${ }^{a}$ Hotchkiss Brain Institute, Department of Clinical Neurosciences, Cumming School of Medicine, University of Calgary, Calgary, AB, Canada

${ }^{b}$ Alberta Child Health Research Institute, Department of Medical Genetics, Cumming School of Medicine, University of Calgary, Calgary, AB, Canada

'Disability Studies, King's University College, Western University, London, ON, Canada

${ }^{\mathrm{d}}$ Corresponding Author: Gerald Pfeffer, Hotchkiss Brain Institute, Department of Clinical Neurosciences, Cumming School of Medicine, University of Calgary, HMRB 155, 3330 Hospital Dr NW, Calgary, AB T2N 4N1, Canada. Email: gerald.pfeffer@ucalgary.ca

doi: https://doi.org/10.14740/jnr665 to identify and may be misattributed to critical illness neuro/ myopathy. When present, neurologic syndromes have been associated with increased mortality in COVID-19 patients [15].

SARS-CoV-2 infects cells via angiotensin-converting enzyme 2 (ACE2), a protein found abundantly among numerous cell types including neurones of the central and peripheral nervous systems, and muscle [16-18]. Therefore, neurologic complications may occur as a direct consequence of viral infection, in addition to neurologic damage resulting from hypoxia, the inflammatory cascade, and other end-organ injuries. As a result, there is concern that patients with pre-existing neurological disorders may be at greater risk of neurological complications, or more severe outcomes in general from COVID-19 [19].

\section{Persons With Pre-Existing Neurological Condi- tions and Rare Diseases, and COVID-19 Risk}

Recent evidence indicates more severe outcomes may occur in patients with common pre-existing neurological disorders [20]. It is more challenging to study the impact of COVID-19 on rare diseases (a large group of individually rare, but collectively common disorders, approximately one-third of which are neurologic) [21]. The available evidence certainly demonstrates a major impact of the pandemic on patients with rare disease in numerous domains [22, 23], including mental health, physical health, and access to care among others. Shifts in healthcare resources to address pandemic needs have directly impacted the care of patients with chronic neurologic conditions [24]. For some specific rare disorders there is evidence for an increased risk of poor outcomes. For example, in trisomy 21 (Down syndrome), the mortality risk is markedly increased compared with the general population [25]. Preliminary evidence from a myasthenia gravis registry suggests severe outcomes may be frequent [26]. Expert opinions agree that many neuromuscular conditions are likely to be associated with increased risk from SARS-CoV-2 infection [27]. This is a highly rational conclusion because patients with neuromuscular disorders are at high risk from pulmonary infections in general [28], and can have compromised respiratory muscle strength at various stages of disease [29]. While there is otherwise limited evidence for specific rare disorders, there is evidence that broader groups of patients, such as those with intellectual and developmental disability, may have more severe outcomes [30]. 


\section{Vaccine Priority for People With Neurological and Rare Diseases}

Persons with neurologic disabilities may have increased risk of contracting SARS-CoV-2 (due to carers entering the home) [31], have reduced access to public health information and health services [32], and have additional challenges during hospitalization if visits from family and other supports are restricted [33]. There is also a bioethical concern that forthcoming intensive care unit (ICU) rationing guidelines [34] could deprioritize the care of those with neurological disorders hospitalized with COVID-19 [35]. The impetus to deprioritized care must be considered in light of regular lack of synchronicity between patient and practitioners' definitions and assumptions of what constitutes "quality of life" with a disability [36-39]. Bureaucratic barriers, such as a focus on recipients of chronic home care as opposed to diagnosis-based priority for phase 1 inoculation, leaves those living with and receiving care from family off priority lists in some municipalities. These decisions are often driven by studies regarding the impact of COVID-19 on persons with disabilities that may be limited due to systemic problems with how data in these populations are collected [40]. Within these communities, individuals have been advised to exercise heightened levels of precaution and vigilance [41], which may result in lower infection numbers and misleading conclusions that patients with neurologic and rare disorders are not at high risk.

There have been calls to prioritize COVID-19 vaccination in persons with intellectual and developmental disabilities [42]. We here suggest that persons with other neurological disorders and rare diseases should also be considered a priority group for vaccination. Neurologic and rare disorders are not considered one of the major risk factors for severe outcomes from SARSCoV-2 infection; nonetheless the evidence clearly shows these patients are vulnerable to direct complications of the virus in addition to elevated risks of exposure due to home care needs and the potential for deprioritized care should they become infected during surging ICU admissions. The impact of SARS-CoV-2 variants of concern, which are more transmissible [43] and virulent [44], adds to the immediacy of this issue. For all these reasons, there is an urgent need to prioritize protecting those with neurologic and rare disorders from contracting COVID-19.

\section{Acknowledgments}

None to declare.

\section{Financial Disclosure}

None to declare.

\section{Conflict of Interest}

None to declare.

\section{Author Contributions}

GP and JP authored the manuscript. SJ edited the work for intellectual content and aided in literature review.

\section{Data Availability}

The authors declare that data supporting the findings of this study are available within the article.

\section{References}

1. Taquet M, Geddes JR, Husain M, Luciano S, Harrison PJ. 6-month neurological and psychiatric outcomes in 236 379 survivors of COVID-19: a retrospective cohort study using electronic health records. Lancet Psychiatry. 2021; 8(5):416-427.

2. Zayet S, Klopfenstein T, Mercier J, Kadiane-Oussou NJ, Lan Cheong Wah L, Royer PY, Toko L, et al. Contribution of anosmia and dysgeusia for diagnostic of COVID-19 in outpatients. Infection. 2021;49(2):361-365.

3. Carrillo-Larco RM, Altez-Fernandez C. Anosmia and dysgeusia in COVID-19: A systematic review. Wellcome Open Res. 2020;5:94.

4. Paliwal VK, Garg RK, Gupta A, Tejan N. Neuromuscular presentations in patients with COVID-19. Neurol Sci. 2020;41(11):3039-3056.

5. Pitscheider L, Karolyi M, Burkert FR, Helbok R, Wanschitz JV, Horlings C, Pawelka E, et al. Muscle involvement in SARS-CoV-2 infection. Eur J Neurol. 2020, Sep 30;10.1111/ene.14564. Online ahead of print.

6. Jardim Vaz de Mello L, Guimaraes Silva E, Oliveira Correa Rabelo G, et al. Neurologic compromise in COVID-19: a literature review. J Neurol Res. 2020;10(5):164172.

7. Reming K, Sivakumar K, Moheb N, Nizam A, Yacoub HA. Late-onset encephalopathy associated with SARSCoV-2 infection. J Neurol Res. 2020;10(6):237-239.

8. Zanin L, Saraceno G, Panciani PP, Renisi G, Signorini L, Migliorati K, Fontanella MM. SARS-CoV-2 can induce brain and spine demyelinating lesions. Acta Neurochir (Wien). 2020;162(7):1491-1494.

9. Chan JL, Murphy KA, Sarna JR. Myoclonus and cerebellar ataxia associated with COVID-19: a case report and systematic review. J Neurol. 2021, Feb 22;1-32. Online ahead of print.

10. Qureshi AI, Baskett WI, Huang W, Shyu D, Myers D, Raju M, Lobanova I, et al. Acute Ischemic Stroke and COVID-19: An Analysis of 27676 Patients. Stroke. 2021; 52(3):905-912.

11. Chan JL, Ebadi H, Sarna JR. Guillain-Barre Syndrome with facial diplegia related to SARS-CoV-2 infection. Can J Neurol Sci. 2020;47(6):852-854.

12. Abu-Rumeileh S, Abdelhak A, Foschi M, Tumani H, Otto M. Guillain-Barre syndrome spectrum associated with COVID-19: an up-to-date systematic review of 73 cases. 
J Neurol. 2021;268(4):1133-1170.

13. Judge C, Moheb N, Castro Apolo R, Dupont JL, Gessner ML, Yacoub HA. Facial diplegia as a rare late neurologic manifestation of SARS-CoV-2 infection. J Neurol Res. 2020;10(6):235-236.

14. Needham E, Newcombe V, Michell A, Thornton R, Grainger A, Anwar F, Warburton E, et al. Mononeuritis multiplex: an unexpectedly frequent feature of severe COVID-19. J Neurol. 2020, Nov 26;1-5. Online ahead of print.

15. Eskandar EN, Altschul DJ, de la Garza Ramos R, Cezayirli P, Unda SR, Benton J, Dardick J, et al. Neurologic syndromes predict higher in-hospital mortality in COVID-19. Neurology. 2021;96(11):e1527-e1538.

16. Xu J, Lazartigues E. Expression of ACE2 in human neurons supports the neuro-invasive potential of COVID-19 virus. Cell Mol Neurobiol. 2020, Jul 4;1-5. Online ahead of print.

17. Fenrich M, Mrdenovic S, Balog M, Tomic S, Zjalic M, Roncevic A, Mandic D, et al. SARS-CoV-2 dissemination through peripheral nerves explains multiple organ injury. Front Cell Neurosci. 2020;14:229.

18. Yamamoto K, Takeshita H, Rakugi H. ACE2, angiotensin 1-7 and skeletal muscle: review in the era of COVID-19. Clin Sci (Lond). 2020;134(22):3047-3062.

19. Manji H, Carr AS, Brownlee WJ, Lunn MP. Neurology in the time of COVID-19. J Neurol Neurosurg Psychiatry. 2020;91(6):568-570.

20. Gao Y, Chen Y, Liu M, Niu M, Song Z, Yan M, Tian J. Nervous system diseases are associated with the severity and mortality of patients with COVID-19: a systematic review and meta-analysis. Epidemiol Infect. 2021; 149:e66.

21. National Institute of Neurological Disorders. Rare Disease Research at NINDS. 2016. https://www.ninds.nih.gov/ News-Events/Directors-Messages/All-Directors-Messages/Rare-Disease-Research-NINDS. Accessed April 8 2021.

22. Chung CC, Wong WH, Fung JL, Hong Kong RD, Chung BH. Impact of COVID-19 pandemic on patients with rare disease in Hong Kong. Eur J Med Genet. 2020;63(12):104062.

23. Sanchez-Garcia JC, Cortes-Martin J, Rodriguez-Blanque R, Marin-Jimenez AE, Montiel-Troya M, Diaz-Rodriguez L. Depression and anxiety in patients with rare diseases during the COVID-19 pandemic. Int J Environ Res Public Health. 2021;18(6).

24. Bersano A, Pantoni L. On being a neurologist in Italy at the time of the COVID-19 outbreak. Neurology. 2020;94(21):905-906.

25. Huls A, Costa ACS, Dierssen M, Baksh RA, Bargagna S, Baumer NT, Brandao AC, et al. Medical vulnerability of individuals with Down syndrome to severe COVID19-data from the Trisomy 21 Research Society and the UK ISARIC4C survey. EClinicalMedicine. 2021;33:100769.

26. Muppidi S, Guptill JT, Jacob S, Li Y, Farrugia ME, Guidon AC, Tavee JO, et al. COVID-19-associated risks and effects in myasthenia gravis (CARE-MG). Lancet Neurol. 2020;19(12):970-971.
27. Association of British Neurologists Guidance on COVID-19 for people with neurological conditions, their doctors and carers. 2020. https://cdn.ymaws.com/www.theabn. org/resource/collection/65C334C7-30FA-45DB-93AA74B3A3A20293/ABN_Neurology_COVID-19_Guidance_ v5 26.3.20.pdf. Accessed April 102021.

28. Benditt JO, Boitano LJ. Pulmonary issues in patients with chronic neuromuscular disease. Am J Respir Crit Care Med. 2013;187(10):1046-1055.

29. Pfeffer G, Povitz M. Respiratory management of patients with neuromuscular disease: current perspectives. Degener Neurol Neuromuscul Dis. 2016;6:111-118.

30. Turk MA, Landes SD, Formica MK, Goss KD. Intellectual and developmental disability and COVID-19 case-fatality trends: TriNetX analysis. Disabil Health J. 2020;13(3):100942.

31. Kuper H, Banks LM, Bright T, Davey C, Shakespeare T. Disability-inclusive COVID-19 response: What it is, why it is important and what we can learn from the United Kingdom's response. Wellcome Open Res. 2020;5:79.

32. Armitage R, Nellums LB. The COVID-19 response must be disability inclusive. Lancet Public Health. 2020; 5(5):e257.

33. PrestonJ.Living with disability in the time ofCOVID. 2020. https://crhesi.uwo.ca/margins/considering-complexlives-value-and-covid-19/. Accessed April 102021.

34. Casey L. Plans for 'life-and-death' ICU triage decisions not finalized, Ont. health minister says. 2021. https://toronto. ctvnews.ca/plans-for-life-and-death-icu-triage-decisionsnot-finalized-ont-health-minister-says-1.5378448. Accessed April 102021.

35. Wilson C. Ontario patients to be ranked for life-saving care should ICUs become full, documents show. 2021. https://toronto.ctvnews.ca/ontario-patients-to-be-rankedfor-life-saving-care-should-icus-become-full-documentsshow-1.5271774. Accessed April 102021.

36. Iezzoni LI, Rao SR, Ressalam J, Bolcic-Jankovic D, Agaronnik ND, Donelan K, Lagu T, et al. Physicians' perceptions of people with disability and their health care. Health Aff (Millwood). 2021;40(2):297-306.

37. Shakespeare T, Iezzoni LI, Groce NE. Disability and the training of health professionals. Lancet. 2009;374(9704): 1815-1816.

38. Tervo RC, Azuma S, Palmer G, Redinius P. Medical students' attitudes toward persons with disability: a comparative study. Arch Phys Med Rehabil. 2002;83(11):15371542.

39. Rousseau MC, Baumstarck K, Billette de Villemeur T, Auquier P. Evaluation of quality of life in individuals with severe chronic motor disability: A major challenge. Intractable Rare Dis Res. 2016;5(2):83-89.

40. Reed NS, Meeks LM, Swenor BK. Disability and COVID-19: who counts depends on who is counted. Lancet Public Health. 2020;5(8):e423.

41. Muscular Dystrophy Canada. What you need to know about COVID-19. 2020. https://muscle.ca/covid-19/whatyou-need-to-know-about-covid-19/. Accessed April 10 2021.

42. Hotez E, Hotez PJ, Rosenau KA, Kuo AA. Prioritizing 
COVID-19 vaccinations for individuals with intellectual and developmental disabilities. EClinicalMedicine. 2021;32:100749.

43. Davies NG, Abbott S, Barnard RC, Jarvis CI, Kucharski AJ, Munday JD, Pearson CAB, et al. Estimated transmissibility and impact of SARS-CoV-2 lineage B.1.1.7 in
England. Science. 2021;372:6538).

44. Adrielle Dos Santos L, Filho PGG, Silva AMF, Santos JVG, Santos DS, Aquino MM, de Jesus RM, et al. Recurrent COVID-19 including evidence of reinfection and enhanced severity in thirty Brazilian healthcare workers. J Infect. 2021;82(3):399-406. 